"I'm perfectly imperfect": Exploring the relationship between PERMA model of wellbeing with self-esteem among persons with disabilities

\author{
Nebrida, Jayson D. $\bowtie$ \\ Central Luzon State University, Philippines (jaysonnebrida029@gmail.com) \\ Dullas, Angelo \\ Central Luzon State University, Philippines (dullas.angelo@yahoo.com)
}

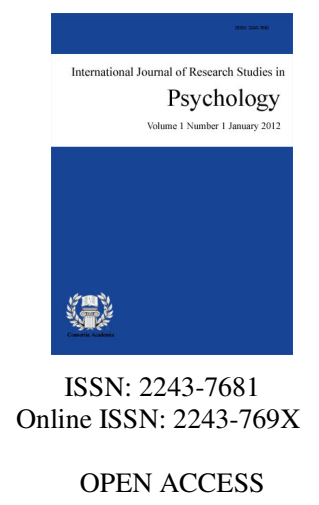

Received: 1 February 2018

Revised: 18 March 2018

Available Online: 2 May 2018

DOI: $10.5861 /$ ijrsp.2018.3005

Accepted: 10 April 2018

\title{
Abstract
}

Most of the studies that measure wellbeing using the PERMA Model were from the school context most commonly students and staffs. In the current study, the new model of wellbeing was applied to the Persons with Disabilities (PWD) and look for its relationship to self-esteem. PERMA Profiler was used in measuring wellbeing for the PWDs and Rosenberg Self-Esteem Scale for their self-esteem. For the result, the study found that PWDs have moderately high level of wellbeing despite of their conditions but low level in self-esteem. There is no difference found in overall wellbeing in terms of sexes but in the two pillars Positive Emotion and Accomplishment, they were significant. For the age relationship to overall wellbeing, there is no relationship found between age and overall wellbeing but weak positive relationship to one of its pillars, Accomplishment. Also to the other factors of the PERMA Profiler, Negative Emotion and Loneliness have found weak relationship with age. For the difference of self-esteem in terms of sexes, there is no difference found. There is also no relationship between age and self-esteem. For the relationship between overall wellbeing and self-esteem, there is no relationship found between the two and even the self-esteem to the different pillars of PERMA. But the other factors of PERMA Profiler like Negative Emotion $(r=.202, p=.043)$ and Health ( $r=.339, p=.001)$ have found weak relationship. Implications indicate in the discussion part of the study.

Keywords: well-being; self-esteem; PERMA; persons with disabilities 


\section{"I'm perfectly imperfect": Exploring the relationship between PERMA model of wellbeing with self-esteem among persons with disabilities}

\section{Introduction}

Human beings are not perfect in nature or simply perfectly imperfect. Being perfectly imperfect defined by Grieger (2013) is the acceptance of individuals to themselves as who they are, and that people are not perfect in nature. This is having positive outlook about the self and being happy as individual despite of the imperfections that human beings have. Despite of the imperfections of human beings, there are people who are facing negative experiences because of the physical imperfections that affect their lives as a whole. These people includes Persons with Disabilities or PWDs. Using the PERMA Model of wellbeing, the main objective of the paper is to explore their happiness and its relation to self-esteem.

It is important to recognize the weakest and the strongest aspect of well-being of an individual. For example, in the application of PEMA model in different studies, if the wellbeing of an individual is very low, PERMA Model will be able to see which part of the pillars or components affect the most of wellbeing of that particular individual. Since PERMA pillars were associated with each other, the other pillars will be expected to be low. On the other hand, by finding the highest score among the pillars, it is possible to start building the holistic wellbeing of that specific individual by enhancing other pillars through that particular pillar. For example, among the 5 pillars, positive relationship has the highest score, the practitioners or caregivers of that individual will have the idea how to start boosting the wellbeing by giving or extending more positive relationship for that specific individual. Since positive relationship is associated with the other 4 pillars of PERMA, positive relationship will serve as the starting point in boosting wellbeing of the said individual. Thus, identifying the pillars of PERMA among PWDs is the main objective of the study. Moreover, there are still lapses in terms of identification of the level PERMA among PWDs. Same is through with the relation of PERMA to Self-esteem although a lot of study were conducted but that is on the relationship between self-esteem and happiness (Tsigilis \& Srebanite, 2015; Lyubomirsky, Tkach, \& Dimmateo, 2006; Baumeister, Campbell, Krueger, \& Vohs, 2003) but not particular on the PERMA per se. Applying the idea to the PWDs, the main objective of this study is by describing the level of 5 pillars of wellbeing as well as the relationship of PERMA to self-esteem.

\section{Review of Related Literature}

\subsection{Context of the PWDs}

Disability is defined as long standing illness and condition that interferes daily activities (Lelkes, 2013). Therefore, Persons with Disabilities are the persons who are experiencing long standing illness and conditions and these specific groups of people are suffering because of their conditions. It is clear that the needs of the Persons with Disabilities are the same as the Persons without Disabilities (Rimmer, Riley, Wang, Rauworth, \& Jurkowski, 2004). They do not want to be categorized as "impaired" or "disabled" but they want to see them as people who also have rights and needs like engaging in social activities to recognize their emotional life, autonomy and aspirations (Colver, 2005). However, the illness and physical limitations that are experiencing by the PWDs have impact on their participation to the other people (Campen \& Iedema, 2007) and experiencing practical and social problems (Kvam, Loeb, \& Tamb, 2007). They were being isolated also by their parents because of the shame about their physical condition (Kandasamy, Prakash, \& Thirusangu, 2009).

Due to PWDs condition, they are also experiencing bullying often than persons without disabilities (Rose, Morda-Amaya, \& Espelage, 2011; Sentenac, Gavin, Arnaud, Molcho, Godeau, \& Gabhainn, 2011; Arseneault, Walsh, Trzesniewski, Newcombe, Caspi, \& Moffitt, 2008; Carter \& Spencer, 2006) and the youngest PWDs are 
Relationship between PERMA model of wellbeing with self-esteem among persons with disabilities reportedly most victimized by bullying (Sentenac et al. 2011). PWDs are being bullied by name calling, teasing, physical attacks, harsh verbal bullying, verbal aggression, threats, taking belongings, imitating of their disability and making fun of them (Carter \& Spencer, 2006). PWDs are also maltreated (Moore, Konrad, Yang, Ng, \& Doherty, 2011) by almost 4 times than their peers without disabilities (Sullivan \& Knutson, 2000) and being abused not just physically but also sexually among PWD women (Plummer \& Findley, 2012).

Because of these negative experiences by the PWDs, negative effects are manifested (Crothers \& Kolbert, 2008). PWDs are dropping out and the worst, they are not enrolling in school (Kandasamy, Prakash, \& Thirusangu, 2009). Because of the situations, PWDs are often more experiencing stress which has direct impact to their family (Gupta \& Singhal, 2004). They are also experiencing anxiety (Kvam, Loeb \&Tamb, 2007) and even depression (Kandasamy, Prakash, \& Thirusangu, 2009; Kvam, Loeb, \& Tamb, 2007) wherein these experiences made them feel very dissatisfied in life (Lelkes, 2013) and very unhappy (Lelkes, 2013; Kandasamy, Prakash, \& Thirusangu, 2009). They also look to themselves as burden to the people around them especially to their family when the members are showing hatred towards them (Kandasamy, Prakash, \& Thirusangu, 2009).

On the other hand, there are existing literatures that look at the positive sides among PWDs wherein the social activities promote psychological wellbeing to the PWDs. Giving importance to their environment that promotes quality of life among PWDs (Yazicoglu, Yavuz, Goktepe, \& Tan, 2012; Lundberg, Bennett, \& Smith, 2011; Colver, 2005). The participation which the PWDs are involved together with their family and the environment will help them to become goal-oriented, family-centered, cooperative, strength-based, ecological, and self-determined (Palisano, Chiarello, King, Novak, Stoner, \& Fiss, 2011). It also promotes subjective wellbeing especially if they perceive that their participation to the different social activities are valuable (Campen \& Iedema, 2007). Their interactions to their co-PWDs also made them happy and cooperative (Kandasamy, Prakash, \& Thirusangu, 2009). Based on literatures cited, there are also ways to promote wellbeing among PWDs and engaging in social activities is one factor to be looked in.

\subsection{The PERMA Model}

Wellbeing is the primary focus in measuring social progress on what weigh much to people (Lelkes, 2013). Wellbeing should be multidimensional (Kern, Waters, Adler, \& White, 2014a) and using multidimensional of wellbeing like PERMA is better than one-dimensional approach of happiness (Sepulveda, 2013). Seligman (2011) defined wellbeing according to his intellect as PERMA - Positive Emotion, Engagement, Relationship, Meaning and Accomplishment - and the goal of developing this concept is to promote psychological flourishing globally.

Positive Emotion is the first element of happiness that Seligman wrote in his book entitled Authentic Happiness (Seligman, 2011). Positive emotions are the emotions that help an individual towards contentment and joy (Butler \& Kern, 2014). Based on the previous study, resilient people are best in using positive emotions (Tugade \& Fredrickson, 2007). The main reason is that positive emotions can reduce stress, helps people to cope and deal with problems and helps to have a clear state of mind (Slavin, Schindler, Chibnall, Fendell, \& Shoss, 2012) and is considered as one of the major components of wellbeing as a science (Fredrickson, 2004; Fredrickson, 1998).

In studying the 25 positive emotions, the reported most evoked emotions were joy, satisfaction, amusement, relaxation, love, confidence and desire (Desmet, 2012). In the broaden-and-build theory, the reported four positive emotions were joy, contentment, interest and love (Fredrickson, 2004; Fredrickson, 1998). In summary, positive emotion is referring to the hedonic or pleasurable feelings of happiness (Seligman, 2011) and different positive emotions promotes wellness and help to achieve short term goals (Griskevicius, Shiota, \& Nowlis, 2010).

Engagement is the psychological connection of an individual to different activities or in specific or different organizations (Butler \& Kern, 2014; Seligman, 2011). Being engaged in different activities and organizations 
and organizations will help individuals to have reflections on what they are doing to become "truly engage" in both positive and negative assets of life and will help patients or individuals on building their emotional, cognitive and spiritual assets in life to help them in creating opportunities and to hold attention in their works (Slavin et al. 2012).

There are several studies that show that engaging in activities lead to skills development, growth in participation and give self-determination (Palisano et al. 2011). Engagement helps reduce mood disturbances, increase competence (Lundberg, Bennett, \& Smith, 2011), increase quality of life (Yazicoglu et al., 2012; Lundberg Bennett, \& Smith, 2011; Colver, 2007) and life satisfaction. Moreover, being engaged in different activities are said to be better than physical therapy and rehabilitations among patients (Yazicoglu et al., 2012) and this will lead in promoting subjective wellbeing (Campen \& Iedema, 2007).

Positive Relationship is a kind of relationship which you feel when you are belonged to the society. This also includes gaining social support and satisfying feelings of social connections (Wilner, 2011; Seligman, 2011) and by being loved and accepted by others (Butler \& Kern, 2014). Previous study stated that having positive relationships with others especially to family members and friends can make teenagers happy (Primasari \& Yuniarti, 2012). It was also found out that social interactions and experiences will help in learning new activities and in developing new skills in engaging in different social activities (Palisano et al., 2011). Moreover, positive relationship shows the importance of the environment to the quality of life especially to young people (Colver, 2005). In addition Seligman (2011) found out that even there is nothing to produce or no productive work in specific group, people will still seek and maintain positive relationships.

Meaning on the other hand, is the belief to self as valuable individual and sees the self to fulfill specific goals and sees life with a sense of purpose (Butler \& Kern, 2014; Wilner, 2011; Seligman, 2011). This sense of meaning in life will help activate and boost mental strength to fight against negativism (Slavin et al., 2012). This also serves as an inspiration (Seligman, 2011). Medical humanities programs are suggested to help students and employees in finding the sense of meaning to their life for them to develop abundance and reflection to their works (Slavin et al., 2012). Dullas and Acoba (2013) on the other hand found out that meaning is the most important element among other domains or pillars of happiness among Filipino farmers with low socio-economic conditions. Similar findings were also found among Filipino children engaged in farming (Tolentino \& Dullas, 2015).

Accomplishment is a process of fulfilling goals, capability in doing daily activities and having perception and sensation about achievement (Butler \& Kern, 2014; Seligman, 2011). Accomplishment also promotes the advancement of new ideas upon culture by empowering employees (or people) to reduce barriers and work with their potentials (Slavin et al., 2012). Having accomplishment views can also build self-confidence and beliefs in futuristic goals (Seligman, 2011) in which achievement related events promote happiness (Primasari \& Yuniarti, 2012).

To summarize the literatures on PERMA, having positive emotion alone cannot promote wellbeing because it is hard to evoke it alone. Engaging in relationship without the presence of positive emotions, without any purpose or meaning and accomplishment will not promote positive relationship. Having positive relationship without engaging is impossible. Having sense of meaning in life without positive emotions and accomplishment is nonsense and accomplishing things without the other four elements is impossible. Thus, one-factor alone cannot work by itself to promote wellbeing. The pillars were interrelated or have direct relationship with each other and that they will work together to promote the totality of wellbeing or happiness of an individual.

\subsection{Self-Esteem}

Self-esteem is a belief to oneself that expresses the attitude in capability, significance, success and worth (Khan, Lanin, \& Khan, 2014). It sees global self-worth by looking at the positive and negative feelings about the self (Park \& Maner, 2009; Rosenberg, 1965). Self-esteem is both social and psychological (Reasoner, 2004) and 
Relationship between PERMA model of wellbeing with self-esteem among persons with disabilities

it is important to define self-esteem from its general term self-concept or the totality of the perception of the people about themselves but the difference of self-esteem to self-concept is that self-esteem is emotional in response in evaluating different things about the self (Heatherton \& Wyland, 2003).

Though personal contacts promote self-esteem (Denissen, Penke, Schmitt, \& van Aken, 2008), other people with low self-esteem enhance their physical appearance to achieve high level of self-esteem and acceptance (Park \& Maner, 2009). Having perfect body image is rewarding in the sense that a person will receive either acceptance and/or appraisal from other people. However, giving too much importance on physical appearance in developing self-esteem may brought negative consequences. For example, the muscularity and body fat give pressure to men which affects their attitudes toward their bodies (Grammas \& Schwartz, 2009) and body dissatisfaction in women leads to perfectionism that predicts bulimic symptoms (Vohs, Voelz, Pettit, Bardone, Katz, Abramson, Heatherton, \& Joiner, 2001).

The level of self-esteem among individuals has seen changes in curves across life span. Over a decade, the level of self-esteem level decreases during adolescent stage mostly among girls and even in old ages (above 60) but high during childhood and adulthood ages (Robins \& Trzesniewski, 2005). But different studies shows that the level of self-esteem increases during young ages (Erol \& Orth, 2011; Orth, Trzesniewski, \& Robins, 2010) and in the middle adulthood stage (Orth, Trzesniewski, \& Robins, 2010), even in adolescence (Erol \& Orth, 2011) and throughout adulthood but the level of self-esteem decreases in old age (Orth, Trzesniewski, \& Robins, 2010). Therefore, different ages in life span of the individuals affect their level of self-esteem.

In sex differences, there is a study that women shows lower self-esteem than men but the curve level of self-esteem meets in the old age (Orth, Trzesnieski, \& Robins, 2010). But the latest study describes that there is no gender differences in terms of self-esteem (Erol \& Orth, 2011). Based on the different literatures of the same researchers, there is still vague difference in the level of self-esteem between men and women particularly among PWDs.

\subsection{Self-Esteem and PWDs}

Maintaining body image in both male and female gives pressure in both sexes in achieving perfect body image (Grammas \& Schwartz, 2009; Vohs et al., 2001) which also associated in self-esteem (Park \& Maner, 2009). But what if there is nothing to be looked perfect in body image? Having imperfections in physical attributes like PWDs which are perfectly imperfect? How do they look towards themselves?

Previous study shows that being self-critic and having personal standards which are the dimensions of perfectionism in higher order increase the fear of closeness with others and decreases self-esteem (Dunkley, Berg, \& Zuroff, 2012). Because of the social, physical contextual and emotional dimensions that serve as barriers to the PWDs, these have direct influence to their self-esteem (Nosek, Robinson-Whelen, Hughes, \& Mackie, 2003) and they become submissive, less pertinent, having low concentration, low social life and low enthusiasm (Lakshmi Nair \& Anuradha, 2014). Since PWDs are being isolated too (Kandasamy, Prakash, \& Thirusangu, 2009), negative manifestations may include self-pity (Akin, 2009) and the permissiveness of the parents especially the mother will cause difficulties in expressing self-esteem (DeHart, Pelham, \& Tennen, 2006). Therefore, the failure of the people around PWDs in recognizing their needs may have big impact in developing healthy general self-esteem (Miyahara \& Piek, 2006) mostly in women with disabilities which are experiencing not just disability but also gender biases (Nosek et al., 2003). Different studies argue that it may end-up in a negative relationship between physical disability and self-esteem wherein lower the self-esteem is expressed (Miyahara \& Piek, 2006).

In the context of the study, though different literatures found that self-esteem is associated with happiness (Tsigilis \& Srebanite, 2015; Lyubomirsky, Tkach, \& Dimmateo, 2006; Baumeister et al., 2003), there are still gaps if this correlation is true among PWDs. Thus, given the context and situations of Filipino PWDs, the main 
Nebrida, J., \& Dullas, A

focused of the study is to verify this relationship.

\subsection{Current Study}

The literatures exposed that there are ways to promote psychological wellbeing among PWDs. The literatures said that through participation in social activities, psychological wellbeing among PWDs were promoted (Yazicoglu et al., 2012; Lundberg, Bennett, \& Smith, 2011; Palisano et al., 2011; Kandasamy, Prakash, \& Thirusangu, 2009; Campen \& Iedema, 2007; Colver, 2005). In summary, one objective of the study is to explore PERMA pillars among PWDs. Looking at the measures of wellbeing through PERMA Model among PWDs is still understudied. According to Seligman (2015; via email), he does not think or even know that there are literatures that looks about the wellbeing of the PWDs through PERMA Model. Thus this is a good contribution of the current study.

In addition, socio-demographic characteristics like sex differences using the PERMA Model is still understudied among PWDs because most the prevailing literatures focused among students (Kern et al., 2014a) and staffs (Kern et al., 2014b; Lovett \& Lovett, 2014). Also, there are existing literatures that support the relationship between happiness and self-esteem wherein happiness have strong and direct relationship to self-esteem (Tsigilis \& Srebanite, 2015; Dogan, Totan, \& Sapmaz, 2013; Lyubomirsky, Tkach, \& Dimmateo, 2006; Baumeister et al., 2003) and using the structural equation modeling, the feedback to the young adults' profiles have direct effect on their self-esteem as well as wellbeing (Valkenburg, Peter, \& Schouten, 2006). But the relationship between self-esteem and the PERMA Model is still understudied among PWDs.

For the current study, the study focused on the wellbeing and the self-esteem of the PWDs. The researcher wants to see the level of wellbeing among PWDs using the PERMA Model, look to their sex differences in the new model of wellbeing and the relationship of their age to wellbeing. Also, the researcher wants to see the level of self-esteem among PWDs, look for the sex differences and the relationship of their age to self-esteem. For the main study, the researcher wants to see if their self-esteem has direct relationship to their wellbeing using the PERMA Model.

The researcher hypothesized that despite of the PWDs' condition, they possessed high level of wellbeing. The researcher also hypothesized that there is a strong positive relationship between age and wellbeing. For their self-esteem, the researcher also hypothesized that PWDs have high level of self-esteem and there is a significant difference between sex and self-esteem wherein males have higher level of self-esteem than female PWDs. It is also hypothesized that there is a strong positive relationship between age and self-esteem. For the main study, the researcher hypothesized that there is a strong positive relationship between the PERMA Model of wellbeing and self-esteem.

\section{Method}

\subsection{Design}

The current study was a quantitative study. Descriptive-correlational is the design that used by the researchers. The study focused on the relationship between PERMA pillars including Negative Emotion and Health and as well as the overall wellbeing, and the Self-Esteem.

\subsection{Participants}

The participants of this study were 101 Persons with Disabilities including blinds, deaf and mute and any related hearing and speech impairment and with orthopedic disabilities due to polio, accident, or naturally born disabilities (from 17 to 60 years old). They were purposively selected by the researchers. Each of the participants completed PERMA Profiler; a 23-item questionnaire which measures the 5 pillars of PERMA including Negative 
Relationship between PERMA model of wellbeing with self-esteem among persons with disabilities

Emotion and Health (Butler \& Kern, 2014) and Rosenberg Self-Esteem Scale (Rosenberg, 1965).

\subsection{Materials}

In the instrumentation, the researcher used the PERMA Profiler, an 11-point scale (from 0-10), 23-item questionnaire which contains the 5 pillars of wellbeing including Negative Emotion and Health to get their overall wellbeing (Butler \& Kern, 2014). For their Self-Esteem, they completed the Rosenberg Self-Esteem Scale, a 10-item questionnaire which measures global self-worth by both positive and negative feelings and perception about the self (Rosenberg, 1965). Both questionnaires were translated to Filipino using back translation. After translating the two scales, it undergone the process of pre-testing. Results showed that PERMA Profiler and Rosenberg Self-esteem Scale Tagalog versions has Cronbach alpha reliability of .842 and .684 respectively.

\subsection{Procedure}

To find the 101 participants, the researcher asked for the assistance to the City Social Welfare and Development in San Jose City, Nueva Ecija, Philippines that is handling the PWD cases. The researcher together with the employees of the CSWD rounded the different barangays of San Jose City to meet the members of the PWD Federation in every barangay and the employees introduced the researcher to their members and asked for their help by answering the two types of questionnaires; the PERMA Profiler and the Rosenberg Self-Esteem Scale that were both translated to Tagalog. Blinds, participants with low visions and uneducated PWDs who were able to rate their wellbeing and self-esteem were assisted by the researchers by reading and explaining to them the instructions and items of the scales. After answering the questionnaires, the researchers showed gratitude to the participants.

\subsection{Data Analysis}

In analyzing the data, the researcher used descriptive and correlational statistics. SPSS version 20.0 was used by the researcher for fast computation of data. For descriptive statistics, the researcher used the mean scores and the standard deviations to see the differences between the sex and the wellbeing pillars and the self-esteem by comparing their mean scores. For the correlational statistics, the researcher used Pearson R Correlation to look for the relationship between age and the PERMA pillars including Negative Emotion and Health and as well as the overall wellbeing, the relationship between age and the Self-Esteem and the relationship between the Self-Esteem and the 5 pillars of PERMA including Negative Emotion and Health and as well as the overall wellbeing.

\section{Results}

This part shows different tables that represents the different objectives of the current study. Different tables represent the level of wellbeing among PWDs, the sex differences with wellbeing, age relationship with wellbeing, level of self-esteem among PWDs, sex differences in terms of self-esteem, age relationship to self-esteem and the relationship to overall wellbeing and its pillars to self-esteem.

Table 1 represents the level overall wellbeing of the participants including negative emotion, health and loneliness. It shows that PWDs have moderately high level of wellbeing $(M=7.09 ; S D=2.15)$ and got the highest score in Meaning $(M=7.45 ; S D=2.56$. The table also shows that female PWDs have higher level of wellbeing than males (Male: $M=6.68, S D=2.28$; Female: $M=7.51, S D=1.94$ ). The tables also shows that in the 5 pillars of PERMA, female PWDs have higher level of Positive Emotion (Male: $M=6.40$, $S D=2.53$; Female: $M=7.63$, $S D=2.15$ ), Engagement (Male: $M=6.08, S D=2.35$; Female: $M=6.25, S D=2.02$ ), Relationships (Male: $M=6.80$, $S D=2.61$; Female: $M=7.65, S D=1.99$ ), Meaning (Male: $M=7.08, S D=2.78$; Female: $M=7.23, S D=2.29$ ) and Accomplishment (Male: $M=6.37, S D=2.42$; Female: $M=7.35, S D=2.14$ ) than males. On the other hand, PWDs 
Nebrida, J., \& Dullas, A

exhibits higher level of negative emotion than male PWDs (Male: $M=4.43$, $S D=2.06$; Female: $M=4.95, S D=1.95$ ). Also, female PWDs have better health than males (Male: $M=6.71, S D=2.38$; Female: $M=7.05, S D=2.16$ ) but loneliness among male PWDs are higher than females (Male: $M=4.67, S D=2.96$; Female: $M=4.54, S D=4.60$ ).

\section{Table 1}

Level of Wellbeing including Negative Emotion, Health and Loneliness

\begin{tabular}{lcccccc}
\hline & \multicolumn{2}{c}{ Male } & \multicolumn{2}{c}{ Female } & \multicolumn{2}{c}{ Total } \\
& Mean & SD & Mean & SD & Mean & SD \\
\hline Wellbeing & 6.68 & 2.28 & 7.51 & 1.94 & 7.09 & 2.15 \\
Positive Emotion & 6.40 & 2.53 & 7.53 & 2.16 & 7.01 & 2.42 \\
Engagement & 6.08 & 2.35 & 6.25 & 2.02 & 6.17 & 2.19 \\
Relationship & 6.80 & 2.60 & 7.65 & 1.99 & 7.22 & 2.35 \\
Meaning & 7.08 & 2.78 & 7.23 & 2.29 & 7.45 & 2.56 \\
Accomplishment & 6.37 & 2.42 & 7.35 & 2.14 & 6.86 & 2.32 \\
Negative Emotion & 4.43 & 2.06 & 4.95 & 1.95 & 4.69 & 2.02 \\
Health & 6.71 & 2.38 & 7.05 & 2.16 & 6.88 & 2.27 \\
Loneliness & 4.67 & 2.96 & 4.54 & 2.97 & 4.60 & 2.95 \\
\hline
\end{tabular}

\section{Table 2}

Sex Differences to Wellbeing including Negative Emotion, Health and Loneliness

\begin{tabular}{lc}
\hline & $p$ value \\
\hline Wellbeing & .053 \\
Positive Emotion & $.010^{* *}$ \\
Engagement & .689 \\
Relationship & .069 \\
Meaning & .140 \\
Accomplishment & $.034^{*}$ \\
Negative Emotion & .190 \\
Health & .462 \\
Loneliness & .832 \\
\hline Note. ${ }^{*} p<.05 \quad * *<.01$ &
\end{tabular}

Table 2 represents the difference between sex and wellbeing including negative emotion, health and loneliness. Table shows that there is no significant difference between sex and wellbeing ( $p=.053)$. The table also represents the differences between sex and the PERMA pillars. The table shows that there is a significant difference between Positive Emotion and sex $(p=.010)$ and Accomplishment and sex $(p=.035)$. The other 3 pillars like Engagement $(p=.689)$, Relationships $(p=.069)$ and Meaning $(p=.140)$ have no significant differences between sex. It also represents the differences between Negative Emotion, Health and Loneliness to sex. The table represents that there is no significant differences between negative emotion to sex ( $p=.190)$, even the health $(p=.462)$ and loneliness $(p=.831)$.

\section{Table 3}

Age Relationship to Wellbeing including Negative Emotion, Health and Loneliness

\begin{tabular}{lcc}
\hline & $r$ value & $p$ value \\
\hline Wellbeing & .166 & .097 \\
Positive Emotion & .156 & .120 \\
Engagement & .137 & .173 \\
Relationships & .094 & .352 \\
Meaning & .155 & .121 \\
Accomplishment & $.257^{* *}$ & .009 \\
Negative Emotion & $.312^{* *}$ & .001 \\
Health & .144 & .150 \\
Loneliness & $.277^{* *}$ & .005 \\
\hline Note. $* * p .01$ & &
\end{tabular}

Table 3 shows the relationship of overall wellbeing (PERMA) to age. The table represents that age has weak 
Relationship between PERMA model of wellbeing with self-esteem among persons with disabilities positive relationship to the overall wellbeing of the participants $(r=.166, p=.097)$. It also represents the relationship between age and the 5 PERMA pillars. It shows that there is a weak positive relationship between age and Positive emotion ( $r=.156, p=.120)$, Engagement $(r=.137, p=.173)$, Relationships $(r=.094, p=.352)$ and Meaning $(r=.155, p=.121)$ but not significant. Accomplishment has weak significant positive relationship to age $(r=.257, p=.009)$. It also shows the relationship of negative emotion, health and loneliness to age. The table represents that age has moderate significant positive relationship to negative emotion $(r=.312, p=.001)$ and loneliness $(r=.277, p=.005)$ and weak positive relationship to health but not significant $(r=.144, p=.150)$.

\section{Table 4}

Level of Self-Esteem

\begin{tabular}{lccc}
\hline \multicolumn{1}{c}{ Sex } & Mean & SD & Description \\
\hline Male & 2.87 & 0.65 & Average \\
Female & 2.90 & 0.33 & Average \\
Total & 2.89 & 0.51 & Average \\
\hline
\end{tabular}

Table 4 shows the level of their level of Self-esteem. The result shows that PWDs have average level of self-esteem $(M=2.89, S D=0.51)$ and female PWDs are reported having higher level of Self-esteem than males (Male: $M=2.87, S D=0.65$; Female: $M=2.90 S D=0.33$ ).

\section{Table 5}

Sex Differences with Self-Esteem

\begin{tabular}{cc}
\hline & $p$ value \\
\hline Self-Esteem & .760 \\
\hline
\end{tabular}

The table shows sex differences with self-esteem. The result shows that there is no significant difference between age and self-esteem $(p=.760)$.

\section{Table 6}

The Relationship between Age and Self-Esteem

\begin{tabular}{ccc}
\hline & $r$ value & $p$ value \\
\hline Age * Self-Esteem & -.004 & .969 \\
\hline
\end{tabular}

Table 6 shows the relationship between Age and Self-esteem. Table 6 shows that the participants' ages have no relationship to the participants' self-esteem but not significant $(r=-.004, p=.969)$.

\section{Table 7}

The Relationship of Self-Esteem to Overall Wellbeing including Negative Emotion, Health and Loneliness

\begin{tabular}{|c|c|c|c|c|c|c|c|c|c|c|}
\hline & 1 & 2 & 3 & 4 & 5 & 6 & 7 & 8 & 9 & 10 \\
\hline 1.Self-esteem & - & .123 & .115 & -.017 & .103 & .142 & .135 & $-.202 *$ & $.339 *$ & -.120 \\
\hline 2.Wellbeing & & - & & & & & & & & \\
\hline 3.Positive Emotion & & & - & & & & & & & \\
\hline 4.Engagement & & & & - & & & & & & \\
\hline 5.Relationships & & & & & - & & & & & \\
\hline 6.Meaning & & & & & & - & & & & \\
\hline 7.Accomplishment & & & & & & & - & & & \\
\hline 8.Negative & & & & & & & & - & & \\
\hline 9.Health & & & & & & & & & - & \\
\hline 10.Loneliness & & & & & & & & & & - \\
\hline
\end{tabular}

Table 7 shows the relationship of the overall wellbeing to the participants' self-esteem. The table represents that self-esteem has no relationship to wellbeing but not significant $(r=.123, p=.221)$. It also represents the relationship of PERMA pillars to self-esteem. The table shows that self-esteem has no relationship to positive 
emotion ( $r=.115, p=.253)$, engagement $(r=-.017, p=.862)$ relationships $(r=.103, p=.306)$, meaning $(r=.142$, $p=.156)$ and accomplishment $(r=.135, p=.178)$. The table also represents the relationship of negative emotion, health and loneliness to self-esteem. The table also represents that self-esteem has weak significant negative relationship to negative emotion ( $r=-.202, p=.043)$, weak positive relationship to health $(r=.339, p=.001)$ and weak no relationship to loneliness $(r=-.120, p=.232)$.

\section{Discussion}

The PERMA Model as a measure of wellbeing is commonly used to measure the overall wellbeing among students (Kern et al., 2014a) and staffs (Kern et al., 2014b; Lovett \& Lovett, 2014). According to Seligman (2015; via email), there are no existing literatures that measure wellbeing among PWDs using the PERMA Model. Also, previous studies using the PERMA Model of wellbeing did not show the sex differences using the new model of wellbeing. Thus, the major contribution of this study is the identification of the level of wellbeing among PWDs and the relationship between PERMA and the concept of self-esteem.

\subsection{Level of Wellbeing}

The results show that PWDs have moderate level of Over-all well-being. They also have moderate level in terms of PERMA pillars. It supports the hypothesis of the study which stated that PWDs have high level of wellbeing despite of their conditions. The factors that may be seen why they portrayed moderate level of wellbeing they were not still fully contented about their life. Even though they get supports from others, other PWD may have fear in engaging to social activities especially the younger PWDs because of the fear of being discriminated or being bullied. Literature said that the most victimized by bullying were the youngest (Sentenac et al., 2011) and this factor may have big impact why PWDs did not get that high level of wellbeing and since their level of Engagement is not that high and actually, it has the lowest level among the scores in the PERMA pillars, the Engagement level of the PWDs must be improved. Literatures suggest that there are ways to promote psychological wellbeing among PWDs like participation to the activities with the one they loved like their families (Palisano et al., 2011) and even with their co-PWDs (Kandasamy, Prakash, \& Thirusangu, 2009) and these promotes wellbeing especially if they think that their participation is valuable (Campen \& Iedema, 2007). One implication is that when their engagement level improve there will be a high tendency that their wellbeing will also be improve because of the interrelationship of Engagement to other pillars of PERMA.

On the other hand, the results show that female PWDs have higher level of wellbeing than males. It rejects the null hypothesis of the study. The researcher came up with the idea of hypothesizing that males have higher level of wellbeing than males is because female PWDs do not just experiencing disability but also gender biases (Nosek et al., 2003). One implication why females are happier than male PWDs is maybe because the cultural orientation of male and female wherein women are expected to be left at home and pay attention to the household chores and to their children while men are expected to work for their families or to be the breadwinner. Because of the disability, men tend to worry for the future especially to those who have their own family and may affect their level of wellbeing. Worrying is one of the reasons of unhappiness. Worrying is a type of negative emotion and the results seemed that the Positive emotion level of males is too low as compared to the females. Male PWDs need to enhance their level of positive emotions. Literature said that positive emotional expressions were affected by individual differences and were connected to personality disability and development especially across adulthood (Harker \& Keltner, 2001). To increase the level of positive emotions, an individual must be participated or involved in different activities that will help their emotion regulation be positive like the acceptance-based, behavioral group-based on multidimensional conceptualization of emotion regulation for 14 weeks which has positive effects to treat different negative emotions (Gratz \& Gunderson, 2006). Goals and activities that an individual must participate must contain positive types, are fit to someone's needs and personality, must be performed and practiced diligently, must be adjusted in their timing and enactment and must be provided a continuous form of positive experiences (Sheldon \& Lyubomirsky, 2007). These different activities will help them to treat negative emotions especially toward themselves and will help 
Relationship between PERMA model of wellbeing with self-esteem among persons with disabilities

them to consider what is good or best about themselves by looking to their selves in a positive way. Sheldon and Lyubomirsky (2006) stated that considering one's best possible selves has a good effect in increasing positive emotions and previous study found that mastery of using positive emotions will help the people to become resilient (Tugade \& Fredrickson, 2007) and this positive emotions is one of the major components of wellbeing (Fredrickson, 2004; Fredrickson, 1998) that promotes wellness and helps to achieve short term goals (Griskevicius, Shiota, \& Nowlis, 2010).

Even females possess higher level of Positive Emotion than males, they also possess higher level of Negative Emotion than male PWDs though in both sexes, they both scored low level in negative emotion. Previous study said that women are more emotionally expressive than men and women may possibly expressed different negative emotions, maybe because of the reason that their income in doing household chores is not that high but the main reason maybe the gender inequality and biases in the family and even in the workplace that they are experiencing (Simon \& Nath, 2004). Female PWDs have also higher level of perception about their current health than male PWDs do but males tend to be lonelier than female PWDs though their scores for that single item (Lonely) are low and this is maybe because of the low level of positive emotions that males have. But if you look at their scores, they are moderately happy about their lives but there are factors to be considered why they are not fully happy and contented about their lives such as the disability and discrimination that they are experiencing. Due to their condition, they have experienced and/or still experiencing bullying (Rose, Morda-Amaya, \& Espelage, 2011; Sentenac et al., 2011; Arseneault et al., 2008; Carter \& Spencer, 2008) and as victims, it has negative effects to them (Crothers \& Kolbert, 2008) like stress (Gupta \& Singhal, 2004), anxiety (Kvam, Loeb, \& Tamb, 2007) and depression (Kandasamy, Prakash, \& Thirusangu, 2009; Kvam, Loeb, \& Tamb, 2007) and these negative experiences lead them to become dissatisfied in life (Lelkes, 2013) and very unhappy (Lelkes, 2013; Kandasamy, Prakash, \& Thirusangu, 2009). But looking to it positively, there are also factors to be seen that made them also lies in the level to live life of being happy despite of their conditions such as having positive relationships and having sense of meaning to life and since it has strong relationship to the other pillars, these two will be the starting point that may help the PWDs to increase more their level of wellbeing that may help them to live their lives to the fullest and become totally wellbeing individuals.

The wellbeing theory that was proposed by Seligman, the PERMA Model is a combination of different pillars to define wellbeing but not a single pillar will define the whole wellbeing (Seligman, 2011). It is expected that in different pillars, there are interrelationship with each other. The idea of the interrelationship is that, when one pillar increases, it is expected that the other pillars will also increase but it does not mean that they are the same in score but their scores are close with each other. This will come up to the idea that just one pillar will need to increase and the level of different pillars will increase and will end up increasing their level of wellbeing. As applied to the current study, it supports what the PWDs attain in every pillar of the PERMA wherein they have reached moderate level in different pillars and their scores in these different pillars are closed with each other.

\subsection{Sex Differences to Wellbeing}

The results show that there is no significant difference between overall wellbeing to the sex orientation of the PWDs but has significant differences in the two pillars of PERMA; the Positive emotion and Accomplishment wherein females have higher level of positive emotion accomplishment than male PWDs. Females are said to be more resilient and goal oriented or with high accomplishment levels than males. It accepts the null hypothesis that there is no significant difference between sexes to wellbeing and males tend to be happier than females because of the experiences that may experience or experiencing by the female PWDs such as gender biases (Nosek et al., 2003) and physical and sexual abuse among PWD women (Plummer \& Findley, 2012) which will never or rarely experiencing by men PWDs. It contradicts the previous study wherein it was said that men are reported that possess positive emotions and women possess negative emotions because women are more emotionally expressive than men (Simon \& Nath, 2004). The result imply that cultural orientation may 
serves as barriers to men wherein men are expected to be the breadwinner of the family but since the disability is present, they may worry on how they will fulfill their duty despite of the disability that they are facing and the main reason of their unhappiness is connected with their disability. This will be a factor to be seen because previous study found that the more the disability occurs, the more the unhappiness level increase (Lelkes, 2013). But looking in relation with the current study, PWDs are in the low level of negative emotion and loneliness of both male and female and possess more positive emotion and even in the 4 pillars than in the others aspects.

\subsection{Age Relationship with Wellbeing}

Using the PERMA Model, there are still no existing literatures that look for the difference or relationship between the new model of wellbeing and the age. In the current study, the researcher found out that age has no significant relationship to wellbeing. But among the PERMA pillars, Accomplishment is the only pillar that is moderately significant to age wherein that as the PWDs are getting older, their accomplishment level increases; it means, there is a small possibility that as they are getting older, they are becoming more goal oriented and see their lives with a sense of purpose despite of the disabilities that they are experiencing. It rejects the null hypothesis that the age has strong significant positive relationship to the different pillars of PERMA as well as the overall wellbeing.

The other factors of the PERMA Profiler like health have no relationship to age but in loneliness, there is a seldom chance that as the age increases, their level of loneliness also increases. On the other hand, the relationship between negative emotion and health showed that when age increases, their level of negative emotions also increases. This may come to the idea that the more they get older, the more they encounter negative experiences like bullying and maltreatment that may cause negative emotions. This idea contradicts the previous studies wherein it was reported that the youngest are the most victimized by bullying (Sentenac et al., 2011), maltreatment (Moore et al., 2011;Sullivan \& Knutson, 2000) by almost 4 times than their peers without disabilities (Sullivan \& Knutson, 2000) wherein these negative emotions will lead to dissatisfaction in life (Lelkes, 2013) and loneliness (Lelkes, 2013; Kandasamy, Prakash, \& Thirusangu, 2009). The number of their accomplishment is also a factor to be seen wherein as they get older the more they fail to see their self-worth ending up to the point where they have negative views towards to themselves. These factors suggested that the younger the age of a PWD, the higher the tendency that he or she will experience loneliness and negative emotion (Miyahara \& Piek, 2006). Their ability to balance emotions in different situations may affect their level of happiness. Previous study stated that the ability to balance emotions in positive and negative experiences has positive effects on happiness (Dogan, Totan, \& Sapmaz, 2013). Lacking of the ability to balance their emotions may lead to unhappiness especially if the experience is worst, there is a possibility that they may fail in balancing their emotions and that may lead to develop negative emotions and possibly affect their level of sense of worth.

\subsection{Level of Self-Esteem}

The results represent that the level of self-esteem among PWDs were average in level. It somewhat accepts the research hypothesis of the study wherein despite of the imperfections in their physical attributes, they possess high level of self-esteem. In addition, the level of self-esteem among male and female PWDs do not vary. This result contradicts the previous study wherein women show lower self-esteem than males do (Orth, Trzesniewski, \& Robins, 2010). Physical imperfections are seemed to be the factor while they don't reach the high level of self-esteem wherein a perfect body image is associated with self-esteem (Park \& Maner, 2009) and being self-critic increase the tendency to not engage with others that is the cause of the decrease to their level of self-esteem (Dunkley, Berg, \& Zuroff, 2012).

\subsection{Sex Differences with Self-Esteem}

Even female PWDs have higher level of self-esteem than males; the results show that there is no significant 
Relationship between PERMA model of wellbeing with self-esteem among persons with disabilities difference between sexes in terms of self-esteem. This result accepts the null hypothesis of the study. The study got the same results as Erol and Orth (2011) wherein there is no significant difference between the two variables; the wellbeing and sex. Thus, the level of the PWDs' self-esteem among different sexes is not that far different with each other but the closeness of their scores indicates that they have almost the same level of self-esteem in terms of sexes. One implication is that they have the same perception about themselves, they do not rate themselves to the higher extremes of score but because they also have positive attitude toward themselves, they do not also rate themselves to the lower extremes and sees that they can also do some things as the persons without disabilities can do.

\subsection{Age Relationship with Self-Esteem}

The result shows that age has no relationship with self-esteem. It shows that age is not a factor to be considered to see level of self-esteem among PWDs. It disproved the alternative hypothesis of the study wherein age has a strong relationship to self-esteem. These contradicts previous studies wherein those show that the level of self-esteem decreases in old ages (Orth, Trzesniewski, \& Robin, 2010) especially above 60 (Robins \& Trzesniewski, 2005) increases during young ages (Erol \& Orth, 2011; Orth, Trzesniewski, \& Robin, 2010) and increases during adolescent stage (Erol \& Orth, 2011). It may also increases in the middle adulthood (Orth, Trzesniewski, \& Robins, 2010) and decreases during adolescent and old-ages (Robins \& Trzesniewski, 2005). As the result of the study, age is not a factor to be considered in terms of self-esteem.

\subsection{The Relationship between Self-Esteem and Wellbeing}

The result shows that self-esteem is not an indicator of wellbeing and it accepts the null hypothesis of the study. The result contradicts the previous studies wherein self-esteem is strongly related to happiness (Tsigilis \& Srebanite, 2015; Dogan, Totan, \& Sapmaz, 2013; Lyubomirsky, Tkach, \& Dimmateo, 2006; Baumeister et al., 2003). The relationship may be affected by the difference of the one-dimensional happiness scale to multidimensional wellbeing like the PERMA wherein the one-dimensional happiness scale only focuses on single item happiness while wellbeing scale like PERMA focuses not just in a single dimension but multidimensional. For example, the mean scores of engagement and positive relationships are far different with each other and if these scores will sum up and look for the mean score, these two factors that have far scores with each other will affect the overall wellbeing of the given data. Another implication is that the context of disability may also affect the relationship of their wellbeing and self-esteem. Though we may consider that they are wellbeing individuals, their physical characteristics may affect their confidence level especially their general self-esteem because of maybe their perceived criticism with regards of themselves. Previous study explains that self-criticism and having personal standards decreases level of self-esteem (Dunkley, Berg, \& Zuroff, 2012) and their physical contextual characteristics that serve as barriers have indirect effect on PWDs self-esteem (Nosek et al., 2003). These factors may affect the relationship of self-esteem to PERMA.

But if we look at the other factors of the PERMA Profiler, negative emotion is negatively correlated to self-esteem and it is significant though it has weak relationship to self-esteem. It means it is substantial that when self-esteem increases, the level of negative emotion will or may decrease and vice versa. But in relation to negative emotion, loneliness is not related to self-esteem. The reason why there is a relationship between self-esteem and negative emotion but not in loneliness even negative emotion and loneliness were under on the same umbrella, this results maybe attributed with the level of the severity of negative emotion than loneliness. Statements about negative emotions for example are about anger and anxiety while loneliness is not. The rating about these two may affect the relationship with self-esteem. Looking for the relationship of health and self-esteem, health is associated with self-esteem wherein the more they perceive that they are healthy, the more they feel confident and look positive towards themselves. The researcher comes up to the idea that PWDs may compensate their physical imperfections to their health to have positive outlook about themselves. This association of health to self-esteem will help the PWDs to practice healthy lifestyle or habits not just to stay 
Nebrida, J., \& Dullas, A

healthy but also to boost their level of sense of self-worth and positive attitude towards their selves.

Overall, since the theory of a single item happiness scale is far different from a multidimensional scale of wellbeing like PERMA, there some factors with strong association with happiness are not associated in wellbeing like the self-esteem. That is why even the previous studies said that happiness is strongly related to self-esteem (Tsigilis \& Srebanite, 2015; Lyubomirsky, Tkach, \& Dimmateo, 2006; Baumeister et al., 2003), in multidimensional approach like in the previous study, we see that there is no association between the two variables and even the pillars on the context of PWDs. But looking for the difference between other variables to happiness or wellbeing, multidimensional approach will be suggested to be used for it is more comprehensive than one-dimensional approach to see what part is weak and what part is strong; what part is high and what part is low to be easily noticed the problems and the factors that will need improvements.

\section{Conclusion and Recommendation}

Results of data analysis show that PWDs were moderately happy and contented on their lives despite of their physical imperfections. Looking at the significant difference in the pillars of PERMA, females are reported to be more resilient than males and higher level of accomplishment. Overall, meaning and positive relationships are the factors to be seen as the starting point in boosting their wellbeing because it scores higher than the other pillars. In addition, age has no association with wellbeing. But there are factors in the PERMA Profiler that has somewhat association with age like the accomplishment and loneliness wherein there is a seldom chance that when the age increases, the accomplishment and loneliness level will increase. The results also show that as the age increases, there is a moderate possibility that the PWDs' negative emotions level will also increase.

In terms of self-esteem, PWDs possess average level of self-esteem and age was also reported no association with self-esteem. Self-esteem is reported as a strong indicator of happiness in the previous studies. But in the current study, self-esteem is reported to have no relationship to the overall wellbeing of the PWDs. Though happiness has an association in self-esteem, the difference between the one-dimensional happiness scale and multidimensional approach of wellbeing may affect the association of self-esteem to wellbeing. Also, the experiences of the PWDs are also factors to be seen why their level of wellbeing and self-esteem are not associated. But their acceptance of being "perfectly imperfect" wherein they accept who they are and what they have as physically imperfect individuals are there, they still need more acceptance about their selves and they need to value more their happiness. This will help them in changing negative beliefs about their selves.

Given the major findings of the study, PWDs got moderately high score of overall wellbeing despite of their conditions. This is a good manifestation that they possess considerable level of well-being despite their conditions. Thus, in relation with results of the study, the following recommendations are made:

1. To make a qualitative study about wellbeing among PWDs to look for the reflection of PERMA through qualitative basis.

2. To look for the difference of wellbeing through PERMA Model between persons with disabilities and persons without disabilities.

3. To look for the disability differences in terms of wellbeing using the PERMA Model.

4. To look for the effect of educational attainment and status in life to wellbeing using the PERMA Model.

5. To develop programs in enhancing well-being using PERMA model among PWDs. 


\section{References}

Akin, A. (2009).Self-compassion and submissive behavior. Education \& Science, 34(152), 138-147.

Arseneault, L., Walsh, E., Trzesniewski, K., Newcombe, R., Caspi, A., \& Moffitt, T. E. (2008). Bullying victimization uniquely contributes to adjustment problems in young children: A nationally representative cohort study. Pediatrics, 118(1), 130-138. https://doi.org/10.1542/peds.2005-2388

Baumeister, R. F., Campbell, J. D., Krueger, J. I., \&Vohs, K. D. (2003). Does high self-esteem cause better performance, interpersonal success, happiness or healthier lifestyles? Psychological Science in the Public Interest, 4(1), 1-45. https://doi.org/10.1111/1529-1006.01431

Butler, J., \& Kern, M. L. (2014).The PERMA profiler. Retrieved from http://www.peggykern.org/uploads/5/6/6/7/56678211/the_perma-profiler_101314.pdf

Campen, C. V., \& Iedema, J. (2007). Are persons with physical disabilities who participate in society healthier and happier? Structural equation modeling of objective participation and subjective well-being. Quality of Life Research, 16, 635-645. https://doi.org/10.1007/s11136-006-9147-3

Carter, B. B., \& Spencer, V. G. (2006). The fear factor: Bullying and students with disabilities. International Journal of Special Education, 21(1), 11-23.

Colver, A. (2005). A shared framework and language for childhood disability. Developmental Medicine \& Childhood Neurology, 47, 780-784. https://doi.org/10.1017/S0012162205001635

Cox, C. R., \& Arndt, J. (2012). How sweet it is to be loved by you: The role of perceived regard in the terror management of close relationships. Journal of Personality and Social Psychology, 102(3), 616-632. https://doi.org/10.1037/a0025947

Crothers, L. M., \& Kolbert, J. B. (2008).Tackling problematic behavior management issue: Teachers' intervention in childhood bullying problems. Intervention in School and Clinic, 43(3), 132-139. https://doi.org/10.1177/1053451207311606

DeHart, T., Pelham, B. W., \& Tennen, H. (2006). What lies beneath: Parenting style and implicit self-esteem. Journal of Experimental Social Psychology, 42(2006), 1-17. https://doi.org/10.1016/j.jesp.2004.12.005

Denissen, J. J. A., Penke, L., Schmitt, D. P., \& van Aken, M. A. G. (2008). Self-esteem reactions to social interactions: Evidence for sociometer mechanisms across days, people and nations. Journal of Personality and Social Psychology, 95(1), 181-196. https://doi.org/10.1037/0022-3514.95.1.181

Desmet, P. M. A. (2012). Faces the product of pleasure: 25 positive emotions in human product interactions. International Journal of Design, 6(2), 1-29.

Dogan, T., Totan, T., \&Sapmaz, F. (2013). The role of self-esteem, psychological well-being, emotional self-efficacy and affect balance on happiness: A path model. European Scientific Journal, 9(20), 31-42.

Dullas, A. R., \& Acoba, E. F. (2013). Concept of happiness among Filipino farmers: A qualitative and quantitative view. Germany: Lambert Academic Publishing.

Dunkley, D. M., Berg, J.-L., \& Zuroff, D. C. (2012).The role of perfectionism in daily self-esteem, attachment and negative affect. Journal of Personality, 80(3), 634-663. https://doi.org/10.1111/j.1467-6494.2011.00741.x

Erol, R. Y., \& Orth, U. (2011). Self-esteem development from age 14 to 30 years: A longitudinal study. Journal of Personality and Social Psychology, 101(3), 607-619. https://doi.org/10.1037/a0024299

Fredrickson, B. L. (1998). What are good positive emotions? Review of General Psychology, 2(3), 300-319. https://doi.org/10.1037/1089-2680.2.3.300

Fredrickson, B. L. (2004). The broaden-and-build theory of positive emotions. Philosophical Transactions of the Royal Society A, 359, 1367-1377. https://doi.org/10.1098/rstb.2004.1512

Grammas, D. I., \& Schwartz, J. P. (2009). Internalization of messages from society and perfectionism as predictors of male body image. Body Image, 6, 31-36. https://doi.org/10.1016/j.bodyim.2008.10.002

Gratz, K. L., \& Gunderson, J. G. (2006). Preliminary data on an acceptance-based emotion regulation group intervention for deliberate self-harm among women with borderline personality disorder. Behavior Therapy, 37, 25-35. https://doi.org/10.1016/j.beth.2005.03.002 
Nebrida, J., \& Dullas, A

Grieger R. (2013). Be perfectly imperfect: Ridding the perfectionism trap. Psychology Today. Retrieved from https://www.psychologytoday.com/blog/happiness-purpose/201304/be-perfectly-imperfect

Griskevicius, V., Shiota, M. N., \& Nowlis, S. M. (2010). The many shades of rose-colored glasses: An evolutionary approach to the influence of different positive emotions. Journal of Consumer Research, 37, 238-250. https://doi.org/10.1086/651442

Gupta, A., \& Singhal, N. (2004). Positive perceptions in parents of children with disabilities. Asia Pacific Disability Rehabilitation Journal, 15(1), 22-35.

Harker, L. A., \& Keltner, D. (2001). Expressions of positive emotion in women's college yearbook pictures and their relationship to personality and life outcomes across adulthood. Journal of Personality and Social Psychology, 80(1), 112-124. https://doi.org/10.1037/0022-3514.80.1.112

Heatherton, T. F., \& Wyland, C. L. (2003). Assessing self-esteem. In S. J. Lopez \& C. R. Snyder (Eds.), Positive psychological assessment: A handbook of models and measures (pp. 219-233). Washington, DC, US: American Psychological Association. https://doi.org/10.1037/10612-014

Kandasamy, V. W. B., Prakash, A. P., \&Thirusangu, K. (2009). Study of the problems of persons with disability (PWD) using FRMs. International Journal of Mathematical Combinatorics, 1, 1-8.

Kern, M. L., Waters, L. E., Adler, A., \& White, M. A. (2014a). A multidimensional approach to measuring well-being in students: Application of the PERMA framework. The Journal of Positive Psychology. https://doi.org/10.1080/17439760.2014.936962

Kern, M. L., Waters, L. E., Adler, A., \& White, M. A. (2014b). Assessing employee wellbeing in schools using an multifaceted approach: Associations with physical health, life satisfaction and professional thriving. Psychology, 5, 500-513. https://doi.org/10.4236/psych.2014.56060

Khan, Z., Lanin, A. B., \& Khan, N. A. (2014). Level of self-esteem among north zone hockey players. Academic Sports Scholar, 3(11), 1-3.

Kvam, M. H., Loeb, M., \& Tamb, K. (2007). Mental health in deaf adults: Symptoms of anxiety and depression among hearing and deaf individuals. Journal of Deaf Studies and Deaf Education, 12(1), 1-7. https://doi.org/10.1093/deafed/en1015

Lakshmi Nair, K., \& Anuradha, S. (2014). Self-esteem among physically disabled and visually disabled late adolescents. International Journal of Technical Research and Applications, 10, 31-39.

Lelkes, O. (2013). Minimizing misery: A new strategy for public policies instead of maximizing happiness. Social Indicators Research, 1-21.

Lovett, N., \& Lovett, T. (2014). Wellbeing in education: Staff matter. International Journal of Social Science and Humanity, 6(2), 107-112. https://doi.org/10.7763/IJSSH.2016.V6.628

Lundberg, N., Bennett, J., \& Smith, S. (2011). Outcomes of adaptive sports and recreation participation among veterans returning from combat with acquired disability. Therapeutic Recreation Journal, 45(2), 105-120.

Lyubomirsky, S., Tkach, C., \& Dimmateo, M. R. (2006). What are the differences between happiness and self-esteem? Social Indicators Research, 78, 363-404. https://doi.org/10.1007/s11205-005-0213-y

Miyahara, M., \& Piek, J. (2006). Self-esteem of children and adolescents with physical disabilities: Quantitative evidence of meta-analysis. Journal of Developmental and Physical Disabilities, 18(3), 219-234. https://doi.org/10.1007/s10882-006-9014-8

Moore, M. E., Konrad, A. M., Yang, Y., Ng, E. S. W., \& Doherty, A. J. (2011). The vocational well-being of workers with childhood onset of disability: Life satisfaction and perceived workplace discrimination. Journal of Vocational Behavior, 79, 681-698. https://doi.org/10.1016/j.jvb.2011.03.019

Nosek, M. A., Robinson-Whelen, S., Hughes, R. B., \& Mackie, P. (2003). Self-esteem and women with physical disabilities (Powerpoint presentation).Center for Reseaocialrch on Women with Disabilities.

Orth, U., Trzesniewski, K. H., \& Robins, R. W. (2010). Self-esteem development from young adulthood to old age: A cohort-sequential longitudinal study. Journal of Personality and Social Psychology, 98(4), 645-658. https://doi.org/10.1037/a0018769

Palisano, R. J., Chiarello, L. A., King, G. A., Novak, I., Stoner, T., \& Fiss, A. (2011).Participation-based therapy for children with physical disabilities. Disability and Rehabilitation, 1-12. 
Relationship between PERMA model of wellbeing with self-esteem among persons with disabilities

Park, L. E., \& Maner, J. K. (2009). Does self-threat promote social connection? The role of self-esteem and contingencies of self-worth. Journal of Personality and Social Psychology, 96(1), 203-217. https://doi.org/10.1037/a0013933

Plummer, S.-B., \& Findley, P. A. (2012). Women with disabilities' experience with physical and sexual abuse: A review of the literature and implications for the field. Trauma, Violence \& Abuse, 13(1), 15-29. https://doi.org/10.1177/1524838011426014

Primasari, A., \& Yuniarti, K. W. (2012). What makes teenagers happy? An exploratory study using indigenous psychology approach. Journal of Research Studies in Psychology, 1(2), 53-61. https://doi.org/10.5861/ijrsp.2012.v1i2.80

Reasoner, R. (2004).The true meaning of self-esteem. Retrieved from http://www.self-esteem-nase.org/what.php

Rimmer, J. H., Riley, B., Wang, E., Rauworth, A., \& Jurkowski, J. (2004). Physical activity participation among persons with disabilities: Barriers and facilitators. American Journal of Preventive Medicine, 26(5), 419-425. https://doi.org/10.1016/j.amepre.2004.02.002

Robins, R. W., \&Trzesniewski, K. H. (2005). Self-esteem development across the lifespan. Current Directions in Psychological Science, 14(3), 158-162. https://doi.org/10.1111/j.0963-7214.2005.00353.x

Rose, C. A., Morda-Amaya, L. E., \& Espelage, D.-L. (2011). Bullying perpetration and victimization in special education. Remedial and Special Education, 32(2), 114-130. https://doi.org/10.1177/0741932510361247

Rosenberg, M. (1965). Society and adolescent self-image. Princeton, NJ: Princeton University Press. https://doi.org/10.1515/9781400876136

Seligman, M. E. P. (2011). Flourish. New York: Free Press.

Sentenac, M., Gavin, A., Arnaud, C., Molcho, M., Godeau, E., \& Gabhainn, S. N. (2011). Victims of bullying among students with a disability or chronic illness and their peers: A cross-national study between Ireland and France. Journal of Adolescent Health, 48, 461-466. https://doi.org/10.1016/j.jadohealth.2010.07.031

Sepulveda, C. I. (2013). Flourishing in Chile: How to increase well-being in the country. Estudos Contemporaneos da Subjevidade, 3(2), 267-275.

Sheldon, K. M., \& Lyubomirsky, S. (2006). How to increase and sustain positive emotion: The effects of expressing gratitude and visualizing best possible selves. The Journal of Positive Psychology, 1(2), 73-82. https://doi.org/10.1080/17439760500510676

Sheldon, K. M., \& Lyubomirsky, S. (2007). Is it possible to become happier? (And if so, how?) Social and Personality Psychology Compass, 1(1), 129-145. https://doi.org/10.1111/j.1751-9004.2007.00002.x

Simon, R. W. \& Nath, L. E. (2004). Gender and emotion in the United States: Do men and women differ in self-reports of feelings and expressive behavior? American Journal of Sociology, 109(5), 1137-1176. https://doi.org/10.1086/382111

Slavin, S. J., Schindler, D., Chibnall, J. T., Fendell, G., \& Shoss, M. (2012). PERMA: A model for institutional leadership and culture change. Response to the 2012 question of the year. Academic Medicine, 87(11), 1481. https://doi.org/10.1097/ACM.0b013e31826c525a

Sullivan, F. M., \& Knutson, J. F. (2000). Maltreatment and disabilities: A population based epidemiological study. Child Abuse and Neglect, 24(10), 1257-1273. https://doi.org/10.1016/S0145-2134(00)00190-3

Tolentino, M., \& Dullas, A. R. (2015). Subjective well-being of Filipino farm children. International Journal of Research Studies in Psychology, 4 (4), 47-60. https://doi.org/10.5861/ijrsp.2015.1265

Tsigilis, N., \& Srebanite, D. (2015). Does self-esteem mediates the association between personality traits and happiness? A structural equation modeling approach. Journal of Social Science Studies, 2(2), 102-116. https://doi.org/10.5296/jsss.v2i2.7370

Tugade, M. M., \& Fredrickson, B. L. (2007). Regulation of positive emotions: Emotion regulation strategies to promote resilience. Journal of Happiness Studies, 8, 311-333. https://doi.org/10.1007/s10902-006-9015-4

Valkenburg, P. M., Peter, J., \& Schouten, A. P. (2006). Friend networking sites and their relationship to 
Nebrida, J., \& Dullas, A

adolescents' well-being and social self-esteem. Cyberpsychology \& Behavior, 9(5), 584-590.

https://doi.org/10.1089/cpb.2006.9.584

Vohs, K. D., Voelz, Z. R., Pettit, J. W., Bardone, A. M., Katz, A., Abramson, L. Y., Heatherton, T. F., \& Joiner, T. Jr. E. (2001). Perfectionism, body dissatisfaction and self-esteem: An interactive model of bulimic symptom development. Journal of Social and Clinical Psychology, 20(4), 476-497. https://doi.org/10.1521/jscp.20.4.476.22397

Wilner, J. (2011). 6 variables that predict happiness and life satisfaction. Adventures in positive psychology with Joe Wilner. Retrieved from

http://blogs.psychcentral.com/positive-psychology/2011/11/6-variables-that-predict-happiness-and-life$\underline{\text { satisfaction }}$

Yazicoglu, K., Yavuz, F., Goktepe, A. S., \& Tan, A. K. (2012). Influence of adapted sports on quality of life and life satisfaction in sports participants and non-sport participants with physical disabilities. Disability and Health Journal, 5, 249-253. https://doi.org/10.1016/j.dhjo.2012.05.003 